\title{
The Design of Enterprise Financial Management Mode Based on the ERP
}

\author{
Kang Yong \\ Henan Institute of Economics and Trade, Henan city, Zhengzhou Province, 450018 \\ 346591653@163.com
}

Keywords: ERP; Financial management; Integrated mode

\begin{abstract}
In recent years, in china, more and more enterprises begin to use the ERP system in the financial management. ERP makes the informationization level of financial management rise to a new height, and the wide application of ERP system brings unprecedented opportunity to enterprise's modern management. How to optimize the financial management mode to improve the quality and efficiency of management is an important issue that the enterprise faces to use the ERP . Through the analysis of the mode selection about the groups' financial management under the environment of ERP, this paper discusses the design optimization model about financial management of company based on ERP, and puts forward the designing method of optimization model to enterprise financial management under the environment of ERP.
\end{abstract}

\section{Introduction}

ERP (Enterprise Resource Planning) is established on the basis of information technology, the use of advanced modern enterprise management ideas and comprehensive enterprise integrated information resources management platform. After the implementation of ERP, the accounting information system of enterprises has been restructured, which can not only quicken the speed of accounting information processing, reducing work intensity of financial personnel, and also improving the efficiency and quality of accounting information. With the development of market economy, a large number of enterprises spring up in our country, and gradually become international, and all of them are the hard core for China's enterprises to compete in the global environment. In order to improve the level of management and enhance competitiveness, enterprises introduced ERP project one after another. The wide applications of ERP lead to the enormous changes of enterprises' internal and external environment, which let financial management, the core of enterprise management, has undergone a transformation too, and the traditional financial management mode gradually failed to adapt to the rapid development of the enterprise group. In this situation, there is an urgent need to construct a new mode of financial management, so as to give full play to the function of financial management and to promote the development of enterprises, then to keep the enterprise group of our country in an invincible position in the fierce international competition. Therefore, the integrated financial management mode based on the ERP came into being. Based on the author's Practical experience, the following passage proposed the design method of optimizing the financial management mode of enterprise under the environment of ERP. 


\section{The Establishment of Comprehensive budget management system}

Under ERP, the integrated financial management creates conditions for the improvement, development and application of comprehensive budget management. ERP integrates the information systems of all enterprises and controls the entire process of enterprise management. And finance, the core of comprehensive budget management is an important approach for ERP to plan in advance and to control thought in process. According to the requirements of the comprehensive budget management, comprehensive budget management system can be divided into three subsystems: Budgeting subsystem, budget control subsystem and budget analysis and evaluation subsystem.

Budget subsystem is a relatively static system, which is used for drawing up the budget of the next year annually. Comprehensive budget management is a systematic project, involving the operating budget, capital budget, financing budget and financial budget. Among them, the operating budget includes sales budget, production budget, direct material budget, direct labor budget, manufacturing budget, production cost budget, sales cost and administrative expenses budget and so on. Capital budget mainly refers to the technical transformation project budget and long-term investment budget. Financing budget is the budget of the short and long term loan enterprises need to borrow in the budget period, the approved bonds, and principal and interest of the original loan and bond. Financing budget includes cash budget, expected profit report, expected balance sheet and statement of cash flow. The reflection of the preparation of budget in ERP is " plan in advance" .

Budget control subsystem is the core of the comprehensive budget management process, and the function of this subsystem is that it can adopt some certain control methods to control the budget programs set in advance in the scope of every subsystem of ERP and provide the corresponding budget control report. It mainly includes 3 modules, the project application, commitment recommendation and payment application. Its basic control method is that a budget program can project, make commitment and pay repeatedly, but the sum of single budget project total project amount should not exceed the budget amount of this program, so do the amount of commitments and payment of single established project. Otherwise, the system will give out prompt information and refuse to accept the excess information, and the information processing work can only be continued when the change of certain budget, project and commitment has been approved.

Budget analysis and evaluation subsystem mainly includes the comparison and analysis of the budget, responsibility center appraisal, and management and integrated query. The main function of the budget comparison and analysis module is to reflect the current situation and development trend of budget responsibility center by using a variety of analysis methods, aiming to prevent the dogmatization of budget execution and to let enterprises adjust the production and business operation plan flexibly. Responsibility center appraisal and management module is used for synthetic assessment and management of the various responsibilities center, aiming to check the completion, distribution of profit and reward and punishment measures of every responsibility center budget. 
Thus, in the ERP system platform, the operational activities, cash flow, accounting, asset management and human resources of enterprises are dynamically incorporated into the budget management system, forming the comprehensive budget management system which covers all of the groups, so as to make full use of the advantage of integrated financial management under the ERP environment, and to realize the beforehand, in-process and post-action control of budget management.

\section{The Construction of Centralized Funds Management System}

Traditional fund management groups have a lot of problems, such as multiple accounts of subordinate units, inefficient monitoring of groups, hard adjustment of internal idle funds and shortage, serious capital precipitation and unreasonable occupancy of enterprises, slow turnaround, decline of enterprises' credit and profitability ability, low efficiency in the use of funds and large capital risk, etc. These are bad for standardizing financial management, influencing group resources integration. Enterprises should apply centralized funds management system, combining the information technology with financial management, and to achieve dynamic management of funds. Construct funds central management model based on the network platform in the aspects of comprehensive budget management of capital, funding decisions and funds settlement, which helps to deploy capital centrally, reduce the cost of the use of funds, improve the efficiency of capital allocation, accelerate the turnover of the fund, then to to play the role of resource integration. Group Corporation can utilize the centralized funds among subsidiaries to adjust the surplus and deficiency, to reduce the loan amount, to help the enterprise to realize the low loan and low cost, so as to enhance the level of company's capital operation, and get the highest return and create the greatest value.

\section{The Establishment of Risk Management System}

To achieve integrated financial management under ERP, it is necessary to establish group financial risk early warning system to dynamically grasp the financial situation of the company and to recognize the sign of the company's financial crisis in advance. The financial crisis early warning subsystem shall include report generation module, indicator generation module, prediction model generation module and real time warning module. Report generation module can automatically generate real-time balance sheet, income statement, cash flow statement, etc., and carry out absolute number analysis, matrix analysis, sequential analysis, comparative analysis, structure analysis and trend analysis; indicator generation module can automatically generate financial ratio indicators, including solvency, profit ability, operating efficiency, growth ability and share index according to the statements; prediction model generation module calls the prediction model and data of the ERP system to figure out whether there exists financial crisis in the finance of group; real-time early warning module works when the financial ratios or other items are beyond the standard value range ,and it will alarm automatically. For example: If the standard value of asset liability ratio is set to $60 \%$, when the asset liability ratio is beyond $60 \%$, then the system will alarm and automatically generate early warning analysis report. 


\section{Sound Internal Financial Control}

Generally, the internal control of financial system under ERP can be divided into general control and application control. General control refers to the overall control of the internal environment relied by enterprises' business operations, including the following aspects: one is organizational control, which is about the division of responsibilities and personnel management control and measures of construction control; the second one is system development and maintenance control, which is to ensure the successful development of ERP system of enterprises; the third one is system security control, including environmental safety control, software safety control, virus prevention and internal audit; the fourth one is operation control, which is achieved by strict and standard operating procedures and carefully enforced work procedures, and its fundamental purpose is to ensure high quality of information processing, to reduce errors and the unauthorized use of documents, programs and reports, including computer room management control, operation right control and operating instruction control; the last one is file control, including accounting data in the computer hard disk and other magnetic media and the written form of accounting data printed out by computer.

Application control, also called operation control, refers to the specific control of the enterprise's production and business activities, which can be divided into input control, processing control and output control. Input the control aims to ensure that business without the approval of business can't enter the computer, to ensure the approved businesses haven't any addition, omission, repetition and improper replacement, and to exclude and correct the incorrect business, which is a key link to guarantee the accounting data authenticity. Data processing control refers to the control set to discover, correct and report some wrong input when operating the computer and to ensure the accuracy and reliability of data processing. The control measures include test account conditions, prevent and control error, modify permissions and modify the trace control. Output control includes strengthening the manual check of output results, and strengthening the distribution and storage of output data.

\section{Implementation of the Financial Officers Appointment System}

In order to give full play to the role of the integrated financial management under ERP, enterprise group headquarters establish special financial department below the board, spearheaded by the chief financial officer of the headquarters to lead the department head and managers of subordinate subsidiaries, which not only guarantees the authority of the headquarters of the group, but ensure the information communication between group headquarters and subordinate the subsidiary, so that timely feedback and reasonable decision-making can be achieved as the managers of subordinate subsidiaries also involve in making decision, then the decision can be implemented effectively. In addition, to establish incentive mechanism under integrated financial management model, there must be a reasonable division of the responsibility and authority of all managers in the group, and the connection between economic benefits and management assets should be more closely. Chief financial officer appointment system is one of the basic ways of financial management of the world's major multinational companies, financial administer of subsidiaries should be appointed by 
the headquarters of the group, and administer appointed must participate in decision-making, so that the financial management of subsidiaries can implement and monitor the entire process of financing. At the same time, the appointed financial administers directly controlled by the headquarters, instead of the management level of subsidiaries, then they can carry out their work better, and strictly obey the provisions of the state and the group, and also correct, disclosure problems in time, which can significantly improve the accuracy and timeliness of accounting in the enterprise and help the group headquarters to carry out effective financial management of the subordinate subsidiary.

\section{Summary}

As the most forefront financial management mode, owing to the limitation of itself and outside environment, integrated financial management mode hasn't been popularized in domestic enterprise group. But with the development of enterprise groups in our country, the perfect of market economy system, and the constantly study and exploration of academic circles and business circles, the integrated financial management mode will gradually become mature and perfect, and become the magic weapon for enterprise group in our country to realize the efficient financial management.

\section{References}

[1]Gao li Jian. To investigate the effect of ERP on enterprise financial management. [J]. 2011, 02:160-161.

[2]Zhang Dan. The application of the ERP in the financial management of Chinese enterprises in foreign trade, 2011, 12:119-120.

[3] Liu Ying. Try to analyze the effect of ERP on accounting and financial management of China's enterprise [J]. value engineering, 2014,10:168-169.

[4]Chi Li Hua. Study on enterprise financial management innovation under the ERP strategy [J]. Journal of Central University of Finance and Economics, 2007, 12:85-89. 